\title{
Judging the Singular: Towards a Contingent Practice of Improvisation in Law
}

\author{
Kathryn McNeilly and Paul Stapleton
}

\author{
Introducing the Contingent
}

In law the role of the judge is seminal, both as a symbolic figure representing justice to the layperson and as the practical arbitrator among competing interests in the adversarial common law system. A canon of thought has emerged pertaining to judges and judicial decision-making: the way in which judges approach the task of responding to each case in front of them, and the resources they use to do so. This includes conventional understandings of the judge's role as that of a detached, neutral mediator, as well as development of substantial critiques of such understandings in the form of procedural justice, therapeutic jurisprudence, and feminist approaches to judging (Hunter et al.). These latter approaches have done much to emphasize the importance of a more active and engaged role for the judge to ensure fairness and respect (Tyler; Lind and Tyler), facilitate emotional, psychological and physical wellbeing of individuals engaged in the justice system (King; Wexler), and be attentive to the gendered nature of law and justice (Hunter) respectively. In this piece, we aim to add to such literature, considering how judicial decision-making, and the skills involved in this activity as a practice of judging the singular, may be productively thought through in terms of improvisation. ${ }^{1}$ The tools of improvisation, and a grasp of improvisation as an important, emancipatory social practice,$^{2}$ facilitate insights into judging which are not possible by other means. From this we encourage judges to consciously think of their role in improvisational terms: to actively engage in a critical practice of improvisation in law that is directed towards enhancing just outcomes for each case they judge on.

In undertaking this exploration we draw upon qualitative interview data with judges working in the area of family law and professional improvising musicians ${ }^{3}$ collected during the course of the Arts and Humanities Research Council funded project Into the Key of Law: Transposing Musical Improvisation. The Case of Child Protection in Northern Ireland. ${ }^{4}$ This project is unique in its interdisciplinary grounding and in engaging the study and discipline of law with that of music. The aim of the project is to draw upon the concepts and practices of improvisation in music to explore space for, and indeed already existing practices of, improvisation in law. Initially, law may seem a highly unlikely site for improvisation given the centrality of tradition, precedent, predictability, and stability in its underpinnings. In fact, the judge-made common law that exists alongside statute law in jurisdictions such as the United Kingdom, Canada, India, Hong Kong, Australia, and the United States of America, offers not only inherent possibilities for, but also requires improvisation in the course of its everyday activity (Ramshaw, Justice). Law is, at its heart, a practice, not a text, involving response to an individual case within a system of precedent using the legal and practical resources that are available. Currently, improvisation appears as a subtle, tacit practice employed by judges, lawyers, and other professionals involved in the legal system, although rarely consciously thought of as such. Here is where productive space exists for improvisational thought to provide insights into judging and for a consciously critical practice of improvisation to emerge.

It is important to note that while we do not wish to merely observe and stay with a tacit practice of improvisation, neither does our work aim to codify improvisation in law-employing an abstract universal idea of what improvisation "is" that could be straightforwardly translated to the legal context. Rather, what we seek to do is to advance a contingent approach to and practice of improvisation in law, one that is grounded in the context within which it takes place and is inherently open to responsive development and change based upon this context. ${ }^{5}$ Improvisation is not a "static" concept engaged in the same way in various contexts and locations; it must be viewed as emerging from particular contexts, constantly shaped, articulated, and rearticulated within and in response to such. To encourage a critical practice of improvisation in law, therefore, we must begin with the contingent. In what follows below, drawing from qualitative data collected as part of the Into the Key of Law project, we engage with what already exists in relation to improvisation in legal practice, judicial work specifically, and use this as a basis to argue for a more conscious development of a critical approach to improvisation in law. By exploring how judges characterize their work and the skills this work involves, we begin to gather a sense of how they engage with improvisation in their everyday role, and where judges' thinking on improvisation and its relation to judicial work may be developed in a more critical and conscious direction. We have broken down discussion into a number of themes where judging can be thought to involve key improvisational elements and judicial skills stand to be explored further, and critically honed, as improvisational: singularity, anticipation, responsiveness/adaptability, and constraint.

\section{Singularity}

Encounters with singularity/generality and the idea of "judging the singular" is a crucial part of the judicial role. Judging singularity within the wider confines of precedent involves judges making use of key improvisational techniques, and the resources of improvisation are useful to think through more closely what is involved in this activity. While judges are bound by a system of common law precedent that requires application of pre-existing rules to the case in front of them, each case remains unique and demanding of a unique response. Each time a 
judge gives judgment they are improvising in the sense of offering a particular result in the particular case they are judging on (MacLean 124). No two cases, however, are the same and the system of precedent, therefore, always involves improvisation in the sense of using and adapting already existing rules in a slightly different or new way each time, rather than merely applying a rule directly. As Sara Ramshaw states,

Improvisation in judgment calls for ongoing, practical decision-making as the constant negotiation between the freedom of the judge to take account of the otherness or singularity of the case and the existing laws or rules that both allow for and constrain that freedom (Justice 3, emphasis in original).

Engagement with singularity is also a key skill of improvising musicians. As musician John Butcher outlines, "You're playing something and listening with the intention of moving from A to B in the next moment, and then something happens in the music, which you hear, and you realize, "Ok, that would be a bad choice. I've got to do something else." Just as improvising musicians must always come to each improvisation anew but with the knowledge and experience of music, their instrument and past improvisational encounters, so too are judges inherently involved in improvisation each time they are called to give judgment in a case. Judges must come to each case anew, must recognise and engage with its singularity, but do so using the legal resources available to them and within the wider temporal context of the case at hand. This latter point is very important in family law cases that may extend over a significant duration.

In our interviews judges did indeed appear to be aware of the tension between singularity and generality characterizing their work, and the need to attentively negotiate the tension between the two. As one judge explained, "The legal principles are straightforward. What is difficult in family work is applying those principles to every single case because every case is so different and so unique." Another judge commented that, "It's very rare that you get identical sort of circumstances in two different cases, and by their very nature the judge has to weigh the competing considerations and decide how much significance to give to this and how much to that." From such comments, judges may already perceive their role as requiring constant navigation of singularity in the context of a wider system of precedent and the need to riff on it each time they judge, and the challenges this can involve. Space exists to build upon this awareness, and to consciously conceptualize this as an improvisatory skill to be honed. A critical practice of improvisation in law would stress the improvisational task of responding to singularity as forming the heart of our common law system. In better recognizing this activity of improvisation, possibilities emerge to foreground the singular and what it demands, how justice can be done in a case. This is especially important in family law where singularity takes on a crucial significance. In the words of one judge, "these cases are very, very fact-specific." In this area of law no two families or situations are the same, and attention to the singularity of each case is particularly important to reach a uniquely just outcome for each child and family. The importance of attention to singularity for the judge in family law work is emphasised by the fact that in this area, in contrast to other areas of civil law or the criminal law, Parliament has afforded judges with a large amount of room for discretion in order to reach the best outcome. ${ }^{6}$ This statute-mandated discretion to facilitate response to the unique facts of family law cases can be thought of as space for improvisation, space to improvise around the singularity of a case to come to a uniquely just result within the context of the system of legal rules and precedent within the area of law more generally. Thinking in this way holds potential to allow judges to further and more consciously engage the tension between singularity and generality in their work and the skills involved in finding an outcome for each case that is unique-tailored justice emerging from the practice of improvisation as citation or iteration of precedent as always (re)iteration in the context of each uniquely singular case.

Recognising the singularity of every case, and the skills of improvisation inherent in the common law system of precedent as (re)iteration and using this to stimulate a conscious, critical practice of improvisation in law, however, also involves something else. It requires recognition that there can be no "right answer" to a legal case. Legal scholar Ronald Dworkin famously asserted, "in most hard cases there are right answers to be hunted by reason and imagination" (Law's Empire viii-ix). For Dworkin, a right answer to a hard case can be found by a judge, presented as a fully knowledgeable and wise Hercules, through employment of legal rules and principles. ${ }^{7}$ This view, however, has been heavily critiqued. Legal realists and the Critical Legal Studies movement have asserted that law is, in fact, indeterminate and that multiple potential answers exist to any legal dilemma (Kennedy; Kress; Tushnet). For such scholarship, the answer a judge delivers depends on a number of factors, including existing law, the time and practical resources available, policy and personal political views, and also the potential for appeal and any damage that may result to their reputation (Kennedy 526-528). Understanding judging through the lens of improvisation builds on the insights of such work; it involves moving beyond the binary of right/wrong, not being constrained by the idea that a right answer to every case exists, and foregrounding that justice is made, not found, invented anew rather than pre-existing. It also adds, however, to such previous work. Conceiving judging as a critical practice of improvisation involves understanding the activity of negotiating the continuum of potential answers to a case as an explicit act of improvisation, and encourages judges to learn how to negotiate this continuum as an improvisational skill. 
Conceptualizing answers to the singularity of a case as existing in multiple forms indeed appears compatible with how some judges already view their role. As one judge we spoke to stated, "There is a range of reasonable responses. It's on a continuum . . . there's certainly plenty of times when it's very hard to know what answer to arrive at." Another judge added that, "There are a range of options available to you and provided you chose one of the options, which fall within the spectrum of reasonable responses to a particular decision, there should not be interference with your judgment." Acknowledging that there is a range of responses to a case encourages a more open and responsive mind, characterizing the judge's function as being about identifying and navigating all possible "answers" to find one that might best respond to the singularity of the case at hand. The skill to be honed is to encourage judges to engage with the entirety of the facts in front of them to reach the answer that best achieves justice. In learning to do so, improvisational resources may be drawn from. These include the ideas of adaptability and listening, which are discussed below. Translated to the legal context, these ideas would encourage judges to stay present with a case, and remain open to negotiation of the spectrum of possible answers before them, in a manner that is informed by engagement with all that surrounds them in the context of a case. Only through careful and holistic attentiveness to singularity and the uniqueness of facts can the best possible answer emerge. Such improvisatory resources can take existing thoughts on judicial practice further, not merely observing that there are multiple answers to a case and highlighting the resources that judges use to reach an answer, but offering tangible tools to facilitate reaching of answers in a way that is grounded in an ethical approach to the world around us.

Acknowledging that there is no "right answer" to be found, which follows from thinking of singularity and generality in legal practice in improvisational terms, may have challenging implications. A critical practice of improvisation includes acknowledging that there is not one right answer to seemingly "clear cut" cases, encouraging a full exploration of all the possible options on the continuum where the tendency may otherwise be to remain blind to these. This is especially the case in family law where the facts judges are dealing with may be harrowing, and pressure is exerted by public opinion and the media in light of highly publicized abuse cases such as Baby $P$ (see Warner), to reach a particular result. As one judge commented, "Well, there are . . . cases where there is an obvious right answer. One of them is a sex abuse case, for example. Significant violence, something of that sort, you know, where really there is nothing else to be done." Embracing a critical improvisational approach, this judge would acknowledge that while on first glance there may appear to be an "obvious right answer," that this cannot be predetermined and exists in a field of other potential answers. Any such answer still requires consideration alongside other possibilities on the continuum to avoid a silencing of singularity and prevention of possibilities for justice to be done. Asserting that there is no "right answer" in such cases does not mean evading taking a tough stance when required, but it does encourage judges to stay with the singularity of every case and to always critically reflect on the range of answers available to them.

\section{Anticipation}

The second theme emerging from our engagements with judges which demonstrates an already existing tacit practice of improvisation in law which stands to be reflected on further is that of anticipation. Anticipation is a key element of improvisation in music. ${ }^{8}$ It offers both possibilities and challenges for improvisers. As musician Maria Chavez comments from her practice,

Anticipation is tricky because there are moments where you want to create a sound, but you're also waiting for the right moment. When I have that moment of anticipation where I want to make that sound, but it doesn't happen for one reason or another, it becomes something completely different. It unexpectedly changes the whole sculpture of the sound piece.

This is a concept that appears to also be highly important to the judicial role. Anticipation emerged from our research as holding potential both to hinder, as pre-judging, but also to enhance, judicial work. The tools of improvisation can assist in making visible both sides of anticipation and provide resources for judges to navigate them.

Naturally, judges may encounter a case and on first reading find they are anticipating what this case is about or what it requires. Following rejection of the idea that there can be a "right answer" to be found, however, it is necessary to look at anticipation in judging in a slightly different way. Understandably, refusing the possibility of a right answer, especially in difficult cases, in favor of a more open response to the singularity of each case may generate anxiety for those engaging in decision-making activity. In addition to the challenge this poses to traditional ways of thinking about law and the judicial role, limited economic resources and a sensitivity to avoid delay in resolving cases may lead to a preference for the general and make it difficult to stay with a foregrounding of the singular. This, taken to its more dangerous and extreme ends, can lead to a tendency to pre-judge, to anticipate what a case is about or what justice in this case would look like without fully engaging with the singular. The critical improvisational approach we are advancing seeks to bring a greater awareness of pre-judging through making the improvisatory role of judges more explicit. While such an approach to pre-judging was not the 
predominant tendency amongst our interviewees, its dangers in judicial work in the contemporary economic context were perceptible. As one judge commented, "don't make a case complicated, unless it has curious or unique features. Most cases don't. By far and away, most cases have more or less the same issues." This is a problematic approach from the perspective of seeking just outcomes, and one that engaging in a consciously critical practice of improvisation would serve to guard against.

In contrast to pre-judging, thinking about judicial decision-making as an inherently improvisational activity and advancing critical engagement with this idea gesture toward the need for anticipation in judicial decision-making that is open, alert, and responsive to singularity. Foregrounding and responding to singularity are not advanced here as involving purely unrestrained activity where judges can never know what the outcome may be and come to the endeavor of judging completely unprepared. Rather, engaging in a critical practice of improvisation involves judges seeking to manage singularity through a number of strategies, one of which is an alertness and anticipation of singularity within a wider context of generality and judicial experience. Judges will bring their experience of past cases and knowledge of law to each new judgment, but instead of allowing this experience to lead to a form of pre-judgment which closes down possibilities for meaningful engagement of what justice in this case may look like, such experience may be employed to aid an alertness. This means adopting a sense of anticipation of what this case might require and might involve which keeps judges engaged with the singular with an eye to precedence and their past experience more generally.

Good judicial decision-making can be regarded as always about anticipation in the form of an alertness grounded in, but not clouded by, experience that is beneficial to the particular case at hand. Improvising musicians also make use of anticipation when they draw on previous knowledge, techniques, and experience to shape their improvisational trajectory, but are willing to let go of these habits if they do not match with the demands of specific moments. The danger of relying too much on prior technique is observed by musician Bennett Hogg who states, "I've played with people who have too much drilled technique in their approach. They are actually difficult to improvise with because there's this level of inflexibility." Musician Bonnie Jones also emphasizes that improvisatory action is not purely spontaneous, not fully unanticipated, as you always act with "the sum total of your experience as a human being up to that point." Accordingly, moves towards a more critical practice of improvisation in law would involve judges being aware of the extent to which they do anticipate, while remaining sensitive to how their experience and knowledge contributes to or impedes this process. Thus, we aim to encourage an alert form of anticipation that is accompanied by an open-minded ability to acknowledge that things can always be otherwise.

\section{Responsiveness/Adaptability}

A third theme emerging from our discussions with judges that appears central to thinking through a critical practice of improvisation in law grounded in contingency is that of responsiveness or adaptability. Skillful improvisers cope with unexpected situations and see opportunities to exploit within these situations.

Musician Matthew Bourne states, "You've kind of a rough idea in mind as to what you are there to do. But, at any given moment that could change; and I think the skill is adapting, and including those disturbances. They are unexpected and do come into the narrative of what you are doing." Clear parallels can be found between the skills of improvisers in this regard and judges. In our interviews, judges stated that a key part of their role was to adapt and respond to facts of a case and also to continue to do so as the case progressed. Family law cases especially involve facts that shift and change throughout the process, often quite dramatically. Being ready to adapt your approach to, or understanding of, a case and to respond accordingly is central to the role of a judge in this area.

The importance of responsiveness and adaptability emerged as central to what judges themselves regard as good judicial decision-making amongst our interviewees. As one judge stated, "it is part of the proper discharge of one's function that one is prepared to change one's mind and should be open to thinking again." Similarly, another judge reflected on the importance of responsiveness and adaptability in the area of family law especially:

It would not be unusual to read a set of papers and have a preliminary view, and then hear oral evidence, or have the evidence tested-insist on the evidence being tested-that the social workers want to give-and forming a very different view. But, as a judge I am used to keeping a very open mind throughout and I think it's vitally important in family work.

Another judge described their experience in the following terms:

Things can seem perfectly logical but then some new piece of evidence emerges or someone looks at a piece of evidence and says something - 'ah, but no, that's not quite what I meant'-and they put a new slant on it, and it's rather like a child playing with a kaleidoscope, you give it a shake and suddenly the picture is quite different. 
Good judicial decision-making, therefore, is adaptable and responsive to the singularity and shifting shape and facts of each case and, furthermore, is consciously aware of the need to be so. This is a key skill that a more conscious, critical approach to improvisation in law would draw attention to. A critical practice of improvisation would seek to build on recognition of the importance of responsive listening and acting in the judge's role and recognition of these elements as skills that need to be honed to effectively respond to the singular. A central part of honing responsiveness and adaptability in a critical practice of improvisation in law is through the idea of listening. To be responsive and adaptive in a way that benefits the interests of justice, judges must really listen to the case in front of them, including, crucially, to the parties involved.

The concept of listening has been dominant in literature surrounding judging and judge-craft, including judicial listening as a skill to be honed (Mack and Anleu). In different ways, all critiques of conventional forms of judging have emphasized the value of listening. This has included listening to the voice of the litigant (procedural justice), active listening and response (therapeutic jurisprudence), and listening to marginalized voices/experiences (feminist judging). ${ }^{9}$ The approach to judging that we advance picks up on such attention to listening in judicial work, but does so drawing on a specific conception of this term which is rooted in critical studies in improvisation and the conception of listening as an important social practice holding emancipatory possibility (Heble and Caines; Oliveros "Deep"). ${ }^{10}$ This goes beyond previous conceptions of listening in the approaches to judging that have emerged to date.

Our interview participants demonstrated an awareness of the crucial difference that listening to voices, such as that of children who are the subject of legal proceedings, can make in judicial decision-making, and to the ultimate outcome of a case, in family law. As one judge stated,

One boy, in particular, stands out in my mind. A boy of 14 , who really changed the direction of the case by wanting to see us, and we then focused on what his concerns were, and tried to identify that to the social workers concerned. It really helped in that case, so, sometimes hearing the voice of the child-as it's often put-is very important.

The approach we are advancing, however, does more than integrate the voice of the child, or other parties, into the case and the judge's decision-making. Rather, it involves introducing an important shift in how judges understand and approach listening in their work.

Critical studies in improvisation stress that listening is a holistic activity that requires mutual communication. Listening emerges, through work such as that of Pauline Oliveros and her influential conception of deep listening (Oliveros Deep Listening; "Deep Listening Meditations"), as an activity that is not simply about hearing but which involves a responsibility to, and interaction with, all that surrounds. Listening in such a deep and attentive way holds the potential to be transformative, to connect us with others and the world around us in a more meaningful manner. Our interviews with improvising musicians reflected this idea of a holistic, active approach to listening. As musician Simon Rose comments, "The problem with listening, or the word "listening," is that very often it's used in a kind of sense like it's dropped in and therefore needs no qualification. But really it needs to be active. Active listening can result in committed playing." In the context of judicial decision-making, where listening is an integral part, approaching this activity through the lens of improvisation indicates that it is not enough to merely listen to someone in a case; to listen effectively to that person a response is also involved. As one judge in our study put it, you must "make that person know they have been heard." A key part of responsiveness to singularity in judicial work, therefore, is responsive listening to adequately engage with singularity in a given case and adapt to its ever-changing form. Our interviews with judges demonstrated that listening is a key element of good judicial decision-making, and of making sure justice is achieved. Thinking of the judge's role as one of improvisation involves beginning to understand and engage in listening as an active and responsive activity, one that is better thought of as characterized by response as opposed to mere hearing. Through actively conceptualizing listening in such a way judges can begin to consider listening in their work as a social practice that holds much potential to facilitate the ends of justice and of wider social change.

\section{Constraint}

As noted above, responsiveness and adaptability to the singularity of each case is not completely spontaneous or unrestrained in the critical approach to improvisation in law that we are advancing. This is why, finally, it is important to engage with the idea of constraint which also emerged in our interviews as a key part of the judge's role and, crucially, of the improvising judge's role. Constraint in judicial decision-making can be thought of in two very different, but inter-related, senses. Firstly, judges often face bureaucratic constraint such as targets, timelines, and limited resources. Such constraint can limit possibilities for effective decision-making and for achieving the best possible, and most just, outcome in a particular case. This type of constraint can be understood as requiring an improvisatory response. Secondly, however, constraint in the judicial role can also be self-imposed where judges actively apply constraints on their work, and that of other professionals around them, 
to productively guide action. Such self-imposed constraints may aid the improvising judge in her role, especially in responding to bureaucratic pressures and so become in themselves an improvisatory response. We will consider each of these ideas of constraint in turn.

In a legal system where limited economic resources and lengthy case times are increasingly prevalent, judges face a myriad of bureaucratic constraints to reduce costs and time spent deciding a case. One example of this in the area of family law is recent reform in England and Wales requiring child protection cases to be processed within twenty-six weeks (see Welbourne). Similar reform has not yet taken place in Northern Ireland where our research took place, but pressure to considerably reduce delay is nevertheless palpable. While the judges we interviewed were indeed concerned to reduce delay, few agreed that introduction of a strict timeline approach was beneficial in terms of reaching a just result, or in assisting judges to respond effectively to the singularity of the case in front of them. As one judge stated, "my own view is, although avoiding delay is important, shoehorning a case into a particular number of weeks, is not necessarily producing the best outcome for the child." Another agreed, expressing the dangers of injustice to the lives involved that could result if a timeline approach was adopted in Northern Ireland: "these are very vulnerable people that we are dealing with, and sometimes people need time to really understand what is expected, and what the requirements are." Such comments, which reflect a broad consensus amongst our interviewees, indicate that bureaucratic constraints are not productive in advancing good judicial decision-making, nor necessarily the interests of justice.

While a critical practice of improvisation does not hold possibilities to solve all bureaucratic constraints placed upon judges, it does offer possibilities to create awareness of spaces and resources that may be drawn upon to work productively within these constraints. Bureaucratic constraint may be productively negotiated in the pursuit of justice through an improvisatory response, using the skills of improvisation more consciously to work with and through bureaucratic challenges. Judging in a context of increasingly demanding constraints imposed from the system itself may be enhanced through foregrounding and consciously utilising improvisational resources such as responsiveness, adaptability, alertness to singularity, and rejection of a "right answer" approach. These resources can offer a counter to bureaucratic constraints, and can help facilitate just outcomes within a system where singularity is being pushed out, encouraging judges to resist attempts to advance cases through the court system by whatever means and as quickly as possible at the expense of justice. Improvisation in the context of bureaucratic constraints such as the proposed twenty-six week timeline in child protection cases does not mean undertaking judgment in a more hasty or less thoughtful way, but indeed the very opposite. It seeks to encourage judges to be especially aware of the dangers of closing their eyes and ears to singularity in the pressure of an over-stretched system, and ensuring that singularity remains foregrounded.

In our discussions with judges, however, a second idea of constraint emerged which may be productively engaged. Constraint can also be detected as a resource productively used by judges in the sense of selfimposed constraint to facilitate good judicial decision-making. One example of this where judges utilize constraint to facilitate effective responses to singularity is that of case management where judges set key dates for action and timetabled a case so to ensure that unproductive delay was minimized. This involved encouraging themselves and other professionals to work to those dates while, unlike the twenty-six week approach above, according flexibility as required. As one judge commented,

Cases have got to be actively case managed. And what that means is at each review you've got to have a purpose. You've got to have read the papers that have come in since the last review, you've got to see whether they raise any more questions that you haven't thought of, and you've got to do something purposeful at the review.

Similarly, another judge explained their approach to such self-imposed constraint in the following terms:

I've already said that [I don't endorse] the guillotine of a particular set of or period of weeks, but, setting regularly reviews, regular court appearances, regular opportunities for parties to object, if something is not being done, or to change direction, if that needs to be done. I think that's the way forward, as far as we're concerned, just to try to keep the cases constantly in front of us, and constantly see what we can do to improve things.

There is evidence of judges adopting such self-imposed constraint as a means of responding effectively to bureaucratic pressures placed upon them, and doing so in a way that works with the resources they have to encourage the best outcome for a case. Another judge explained their approach in the following terms:

I have kicked ass around my court day in and day out, and demanded that assessments were done more quickly than I was told they could be done. There is delay everywhere. If there has to be an assessment, "well, we have to make a referral first to the resource panel to see will they pay for it," even though the judge has said, "I want it done." Then there will be a waiting list possibly for the family center, then the family center not unusually will say: "we're not going to do any work until we have a psychological assessment of the parents" ... so my approach was to take every single case 
and, in respect of every aspect of the case, look at ways in which things could be done more quickly - practical ways - it has to be done very practically for a judge. But it was very, very hard work. And, I was up against a massive system where delay is endemic.

In this sense, positive constraints placed by the judge on herself and other professionals involved in the case to progress it more effectively can be a powerful tool, and looking for opportunities where this can be done is essential in a system where time and resources are limited. The key is to hone this skill in a way that differs from a bureaucratic approach driven by statistics as opposed to the interests of particular cases. A critical approach to improvisation can fulfill this purpose, stressing the importance of fluidity, responsiveness, and adaptability as crucial to justice, but as taking place not in a fully free way, but within the context of constraint as a useful and necessary part of managing complexity. As musician David Borgo says, "the artist's role is to show how we can gracefully deal with surprise and complexity." To aid in this process, musician Ellen Waterman emphasizes the productive nature of employing constraint in the form of rules: "I like the idea of rules for play. We don't operate outside of a context. It's very important that we learn how to use rules and relate to rules in a positive way." Constraint, self-imposed constraint especially, is an important element guiding any improvisational activity and one which judges appear already to be engaging with to enhance just outcomes. This is an integral part of the improvising judge's role, especially in contingent settings of stretched resources and endemic delay.

\section{Conclusion}

From the above analysis and our discussions with judges and musicians a key realization emerges: many judges are already expert improvisers, using a range of improvisational resources to manage the difficult activity of judicial decision-making. Improvisation is already happening in law, and indeed is a crucial thread weaving through judicial work. Space does exist, however, to think through further, or more consciously, the improvisational elements of the judicial role and judicial skills. When we do this a critical practice of improvisation may begin to emerge within law that aims to foreground the singular and offers tools to productively advance the aims of justice in a challenging and demanding system. While the insights and experiences of musical improvisation are useful in this emerging approach to improvisation in law, this approach must be considered as fundamentally contingent-emerging, evolving, and shifting in relation to the specific context of law and particular contexts for judging.

In thinking through such a contingent approach to improvisation in law, it is important to recognize that judges are the experts who are highly skilled in employing a number of improvisation skills already in their everyday decision-making. The legal system must recognize this expertise to allow judges to make the best decisions. Indeed, our research shows that this is not just the case for judges, but also for other professional legal practitioners who often feel similarly restricted by the bureaucratic system within which they operate. This system demonstrates trends towards a marginalization of singularity, limited space for effective and holistic listening, responsiveness and adaptability as well as an advancement of bureaucracy over expertise. Even if the system cannot change, however, judges and other legal professionals can. The improvisatorial nature of law, judicial decision-making in particular, and judges' expertise as improvisers stands to be more consciously recognized and engaged with by these professionals themselves. Bringing this improvisatorial expertise into view is something that needs to be developed, fostered, and practiced, just like any other skill.

In advancing a critical approach to improvisation, we suggest that foregrounding contingency is crucial, foregrounding improvisation itself as a context-specific activity capable of development in new ways to better meet ever-emerging challenges in diverse locations from music to law. Our advancement of a contingent approach to improvisation in law in this sense has implications for how we understand the concept of improvisation more generally. It is essential that as a concept and practice improvisation is kept unsettled, embraced as an open-ended ideal as opposed to a static and abstract concept. In doing so we are retaining a critical perspective to improvisation itself, to how we conceptualize it more broadly, and to what it might become in the future. Just as a critical approach to improvisation is required in law to challenge spaces of comfort which do not serve the ends of justice, so too is a critical approach to the idea of improvisation itself imperative, rejecting the comfort of a false, abstract universal, in order to retain the critical force that the concept and practice of improvisation may offer.

\section{Notes}

${ }^{1}$ This is very much an emergent area of thought. For related work see Ramshaw, Justice; Ramshaw, "Jamming"; Manderson; Piper; Marisi.

\footnotetext{
${ }^{2}$ See, for example, Fischlin; Fischlin and Heble; Heble and Waterman; Heble and Siemerling; Heble.
} 


\begin{abstract}
${ }^{3}$ Due to the sensitive nature of judicial decision-making generally, and in the context of Northern Ireland in particular, all direct quotations from judicial interview participants have been anonymized. Musicians have consented to use of full names.
\end{abstract}

${ }^{4}$ The project is directed by Sara Ramshaw (PI) and Paul Stapleton (Co-I). For further information visit: http://www.translatingimprovisation.com/ahrc

${ }^{5}$ For discussion on this point thoughts may be directed to Judith Butler's conception of the relationship between universality and contingency (“Universality"; Undoing 190-191; Butler, Laclau and Žižek).

${ }^{6}$ See, for example, the idea of the "welfare of the child" in Article 3 of the Children Order (NI) 1989 which is the paramount consideration guiding judicial decision-making in child law cases, but offers room for wide discretion as to what this requires in a particular case.

7 See also Dworkin Taking Rights; Dworkin “No Right."

${ }^{8}$ For wider discussion of anticipation and music more generally see Huron. For a cognitive science approach to understanding music improvisation where anticipation is quantitatively studied see Pressing.

${ }^{9}$ In the context of family law, the area pertinent to our project, the need to listen to the voice of the child, and the absence of such voices from legal proceedings, has also been a dominant theme (Raitt; Parkinson and Cashmore; Taylor).

10 See generally "Part 1: Listening" in The Improvisation Studies Reader (Heble and Caines, eds.), which features texts on the subject of listening by George Lipsitz, Jean-Luc Nancy, Ingrid Monson, Pauline Oliveros, and others.

\title{
Works Cited
}

Butler, Judith, Ernesto Laclau and Slavoj Žižek. Contingency, Hegemony, Universality: Contemporary Dialogues on the Left. Verso, 2000.

Dworkin, Ronald. Law's Empire. Harvard University Press, 1986.

---. “No Right Answer?” New York University Law Review, vol. 53, no. 1, 1978, pp. 1-32.

---. Taking Rights Seriously. Harvard University Press, 1978.

Fischlin, Daniel. "Wild Notes' . . Improvisioning." Critical Studies in Improvisation vol. 6, no. 2, 2010, pp. 1-10. http://www.criticalimprov.com/article/view/1358.

Fischlin, Daniel and Ajay Heble. "The Other Side of Nowhere: Jazz, Improvisation, and Communities in Dialogue." The Other Side of Nowhere: Jazz, Improvisation, and Communities in Dialogue, edited by Daniel Fischlin and Ajay Heble, Wesleyan University Press, 2004, pp. 1-42.

Heble, Ajay. Landing on the Wrong Note: Jazz, Dissonance, and Critical Practice. Routledge, 2010.

Heble, Ajay and Rebecca Caines. "Prologue: Spontaneous Acts." The Improvisation Studies Reader: Spontaneous Acts, edited by Ajay Heble and Rebecca Caines, Routledge, 2014, pp. 1-6.

Heble, Ajay and Winfried Siemerling. "Voicing the Unforeseeable: Improvisation, Social Practice, Collaborative Research." Canadian and Global Imaginaries in Dialogue, edited by Diana Brydon and Marta Dvořák. Wilfred Laurier UP, 2012, pp. 39-52.

Heble, Ajay and Ellen Waterman. "Sounds of Hope, Sounds of Change: Improvisation, Pedagogy, Social Justice." Critical Studies in Improvisation, vol. 3, no. 2, 2007, pp. 1-4. http://www.criticalimprov.com/article/view/409/620.

Hunter, Rosemary. "Feminist Judgments Projects: Legal Fiction as Critique and Praxis" International Critical Thought, vol. 5, 2015, pp. 501-508.

Hunter, Rosemary, Sharyn Roach Anleu, and Kathy Mack. "Judging in Lower Courts: Conventional, Procedural, Therapeutic and Feminist Approaches." International Journal of Law in Context, vol. 12, no. 3, 2016, pp. 337-360. 
Huron, David Brian. Sweet Anticipation: Music and the Psychology of Expectation. MIT Press, 2006.

Kennedy, Duncan. "Freedom and Constraint in Adjudication: A Critical Phenomenology." Journal of Legal Education, vol. 36, 1986, pp. 518-562.

King, Michael. "Applying Therapeutic Jurisprudence From the Bench." Alternative Law Journal, vol. 28, no.4, 2003, pp. 172-175.

Kress, Ken. "Legal Indeterminacy.” California Law Review, vol. 77, no. 2, 1989, pp. 283-337.

Lind, E. Allan and Tom Tyler. The Social Psychology of Procedural Justice. Plenum Press, 1988.

Mack, Kathy and Sharyn Roach Anleu. "Opportunities for New Approaches to Judging in a Conventional Context: Attitudes, Skills and Practices." Monash University Law Review, vol. 37, no. 1, 2011, pp. 187-215.

MacLean, James. Rethinking Law as Process: Creativity, Novelty, Change. Routledge, 2012.

Manderson, Desmond. "Fission and Fusion: From Improvisation to Formalism in Law and Music." Critical Studies in Improvisation, vol. 6, no.1, 2010, pp. 1-10. http://www.irss.uoguelph.ca/index.php/csieci/article/view/1167/1726.

Marisi, Flavia. "Musical Improvisation and Judicial Activism." Review of Artistic Education, vol. 7-8, 2014, pp. 3439. https://www.questia.com/library/journal/1P3-3414387701/musical-improvisation-and-judicialactivism.

Oliveros, Pauline. Deep Listening: A Composer's Sound Practice. iUniverse, 2005.

---. “Deep Listening Meditations: Egypt (1999).” The Improvisation Studies Reader: Spontaneous Acts, edited by Ajay Heble and Rebecca Caines, Routledge, 2014, pp. 52-53.

Parkinson, Patrick and Judy Cashmore. The Voice of a Child in Family Law Disputes. Oxford UP, 2010.

Piper, Tina. "The Improvisational Flavour of Law, the Legal Taste of Improvisation." Critical Studies in Improvisation, vol. 6, no. 1, 2010, pp. 1-5. http://www.criticalimprov.com/article/view/1191/1725.

Pressing, Jess. "Cognitive Processes in Improvisation." Advances in Psychology, vol. 19, 1984, pp. 345-363.

Raitt, Fiona. "Hearing Children in Family Law Proceedings: Can Judges Make a Difference?" Child and Family Law Quarterly, vol. 19, no. 2, 2007, pp. 204-224.

Ramshaw, Sara. "Jamming the Law: Improvisational Theatre and the 'Spontaneity' of Judgment." Law TextCulture, vol. 14, no. 1, 2010, pp. 133-159.

---. Justice as Improvisation: The Law of the Extempore. Routledge, 2013.

Taylor, Nicola. "The Voice of the Child in Family Law." Children's Legal Rights, vol. 18, no. 1, 1998, pp. 2-14.

Tushnet, Mark. "Defending the Indeterminacy Thesis." Quinnipiac Law Review, vol. 16, no. 3, 1996, pp. 339-356.

Tyler, Tom. "Procedural Justice, Legitimacy and the effective Rule of Law." Crime and Justice, vol. 30, 2003, pp. 283-357.

Warner, Joanne. "'Heads Must Roll'? Emotional Politics, the Press and the Death of Baby P." British Journal of Social Work, vol. 44, no. 6, 2014, pp. 1637-1653.

Welbourne, Penelope. "Time is of the Essence: Risk and the Public Law Outline, Judicial Discretion and the Determination of a Child's Best Interests." Social Sciences, vol. 3, no. 3, 2014, pp. 584-605. http://www.mdpi.com/2076-0760/3/3/584.

Wexler, David. "Therapeutic Jurisprudence: An Overview.” Thomas M. Cooley Law Review, vol. 17, no. 1, 2000, pp. 125-134. 